\begin{tabular}{|c|c|c|}
\hline \multirow{3}{*}{$\begin{array}{r}\text { Case Reports in } \\
\text { Gastroenterology }\end{array}$} & \multirow{2}{*}{\multicolumn{2}{|c|}{ Case Rep Gastroenterol 2015;9:307-310 }} \\
\hline & & \\
\hline & $\begin{array}{l}\text { DOI: } 10.1159 / 000440695 \\
\text { Publisnea onine:. September 17, } 2015\end{array}$ & $\begin{array}{l}\text { (c } 2015 \text { S. Karger AG, Basel } \\
\text { 1662-0631/15/0093-0307\$39.50/0 } \\
\text { www.karger.com/crg }\end{array}$ \\
\hline & \multicolumn{2}{|c|}{$\begin{array}{l}\text { This is an Open Access article licensed under the terms of the Creative Common } \\
\text { Attribution-NonCommercial } 3.0 \text { Unported license (CC BY-NC) (www.karger.com/OA } \\
\text { license), applicable to the online version of the article only. Distribution permitted for non } \\
\text { commercial purposes only. }\end{array}$} \\
\hline
\end{tabular}

\title{
A New Etiology for the Abdominal Compartment Syndrome: Pseudomyxoma Peritonei
}

\author{
Charles Sabbagh $^{\mathrm{a}} \quad$ Colette Vaillandet $^{\mathrm{a}} \quad$ Jean-Jacques Tuech $^{\mathrm{b}}$ \\ Jean-Marc Regimbeau ${ }^{a}$ \\ ${ }^{a}$ Department of Digestive and Metabolic Surgery, Amiens University Hospital, University \\ of Picardie Jules Verne, Amiens, and ${ }^{b}$ Department of Digestive Surgery, Rouen University \\ Hospital, Rouen, France
}

\section{Key Words}

Pseudomyxoma $\cdot$ Compartment syndrome $\cdot$ Emergency $\cdot$ Hyperthermic intraperitoneal chemotherapy · Surgery

\begin{abstract}
Pseudomyxoma peritonei (PMP) is a rare diagnosis with an incidence of 1-2 per million. Most cases originate from an appendix which ruptures and releases mucin into the peritoneal cavity. The progression of the disease results in obstruction and cutaneous leak. Abdominal compartment syndrome is an uncommon complication of peritoneal pseudomyxoma. In the present article, we report the case of a patient with PMP and abdominal compartment syndrome. A laparotomy to decrease the abdominal pressure was performed. Three months later, a peritonectomy with hyperthermic intraperitoneal chemotherapy was performed. The patient was still alive 1 year after the procedure without any recurrence. In conclusion, acute abdominal pain and respiratory failure in patients with peritoneal PMP should lead to the measurement of the abdominal pressure but are not a contra indication for curative treatment of PMP.

(c) 2015 S. Karger AG, Basel
\end{abstract}

\section{Introduction}

Pseudomyxoma peritonei (PMP) is a rare diagnosis with an incidence of 1-2 per million. Most cases originate from an appendix which ruptures and releases mucin into the peritoneal cavity. The progression of the disease results in obstruction and cutaneous leak. Preopera- 
Sabbagh et al.: A New Etiology for the Abdominal Compartment Syndrome: Pseudomyxoma Peritonei

tive abdominal and chest CT scan and serum tumour markers are the investigations for PMP and can help predict the feasibility of cytoreduction. Most patients have no symptoms or abdominal distension, but abdominal compartment syndrome is an uncommon presentation of PMP. We report a case of such a complication.

\section{Case Report}

The patient was a 55-year-old woman admitted to the emergencies for periumbilical abdominal pain. In her past medical history, a PMP on abdominal distension had recently been discovered without any surgical procedure. At the examination, the patient presented with acute dyspnea for $24 \mathrm{~h}$. It quickly developed into acute respiratory distress that needed an orotracheal intubation. The blood gases showed hypoxemia (60 $\mathrm{mm} \mathrm{Hg}$ ) and hypercapnia (45 mm Hg). The chest abdominal CT scan showed that the mucin had increased compared to the former CT scan. The abdominal compartment syndrome suspected on these clinical and paraclinical data was confirmed by the measurement of the intravesical pressure in the supine position ( $30 \mathrm{~mm} \mathrm{Hg}$ ). A punction under ultrasound control was performed on the abdominal midline but failed due to the consistency of the mucin. A laparotomy to decrease the abdominal pressure was performed. The operative procedure included an omphalectomy, an omentectomy and an appendicectomy. This operation treated the abdominal compartment syndrome (fig. 1). Three months after surgery, a peritonectomy with hyperthermic intraperitoneal chemotherapy (HIPEC) was performed. The peritoneal cancer index score was 30. A complete peritonectomy (CC0) was performed; no other organ resection was necessary. The operative time was $600 \mathrm{~min}$; chemotherapy agent was mitomycin $15 \mathrm{mg} / \mathrm{m}^{2}$ at $43^{\circ} \mathrm{C}$ for $30 \mathrm{~min}$. There was no postoperative complication. The patient is still alive 1 year after the procedure without any recurrence (fig. 1).

\section{Discussion}

The abdominal compartment syndrome is an emergency and needs to be treated to avoid life-threatening conditions. In a recent review, Moore et al. [1] defined an abdominal hyperpressure as a pressure over $20 \mathrm{~mm} \mathrm{Hg}$. They also showed that at a pressure of over 26 $\mathrm{mm} \mathrm{Hg}$, organ failures were possible. The survival rate after an abdominal compartment syndrome is 53\% [1]. The etiology of the abdominal compartment syndrome consists of conditions that are diminishing the abdominal wall compliance (abdominal surgery, abdominal trauma), increasing the intraluminal contents (gastroparesis, ileus) and increasing the abdominal volume (acute pancreatitis, hemoperitoneum, tumours) [2]. The treatment of abdominal compartment syndrome has been standardized by an international conference consensus published in 2007 [3]. The first step is to consider medical treatment including treatment to improve abdominal wall compliance (analgesia, sedation, neuromuscular blockade, body positioning) and evacuation of intra-abdominal contents (nasogastric tubes, colonic decompression, abdominal prokinetics) and to correct a positive fluid balance (fluid restriction, diuretics, haemodialysis). The second step is to consider surgical decompression. Surgical procedure is a life-saving intervention when a patient's intra-abdominal hypertension has become refractory to medical treatment options. Surgical procedure is actually a surgical decompression by opening the abdominal wall and leaving the abdomen open. The abdomen is then covered by a device (Bogota bag, vacuum-pack closure) or by the closure of the skin [3]. 
Sabbagh et al.: A New Etiology for the Abdominal Compartment Syndrome: Pseudomyxoma Peritonei

Peritoneal pseudomyxoma is a good prognostic tumour when a complete cytoreduction in combination with HIPEC is performed. There are a number of classifications for PMP. A classification by the WHO divided PMP into low and high grade. This classification and the level of the preoperative serum tumour markers are the more important prognostic factors. In the largest series, Chua et al. [4] reported a median overall survival of 16.3 years and a 15year survival rate of 59\%. The prognostic factors are CC0 resection and the histological type of pseudomyxoma (low or high grade) [4]. In a study by Taflampas et al. [5] in Basingstoke, the mean overall survival was 168 months (range: 128-207) compared with 65 months (range: $42-88$ ) when markers were elevated $(p=0.002)$.

No specific data is available on the emergency and peritoneal pseudomyxoma. The most frequent one are ileus, abdominal wall leak with mucin and ureteral compression [6]. Bowel obstruction is a serious complication of PMP. In most cases, there are no clinical signs of obstruction, but bowel loops are dilated on CT scan. Bowel dilatation and mesenteric mass of more than $5 \mathrm{~cm}$ are the two prognostic factors on CT scan. When both signs are present, there is an $88 \%$ probability of incomplete resection, whereas when no signs are present, the probability of complete resection is $92 \%$. To the best of our knowledge, this is the first case of abdominal compartment syndrome to be reported. The management of such cases needs to take into account HIPEC as a curative treatment in the near future of the patient's treatment. Thus, the procedure has to be as conservative as possible and dissection has to be limited. Peritonectomy and HIPEC is the only curative treatment of peritoneal pseudomyxoma, but the morbidity rate is $12-67 \%$ and the mortality rate is $0-9 \%$ [7].

Abdominal compartment syndrome is a rare emergency of peritoneal pseudomyxoma, but it has to be considered as a possible explanation of abdominal compartment syndrome. Acute abdominal pain and respiratory failure in patients with peritoneal pseudomyxoma should lead to the measurement of the abdominal pressure.

\section{Statement of Ethics}

The authors have no ethical conflicts to disclose.

\section{Disclosure Statement}

None of the authors has any conflict of interest.

\section{References}

1 Moore AF, Hargest R, Martin M, Delicata RJ: Intra-abdominal hypertension and the abdominal compartment syndrome. Br J Surg 2004;91:1102-1110.

-2 Kirkpatrick AW, Roberts DJ, De Waele J, Jaeschke R, Malbrain ML, De Keulenaer B, Duchesne J, Bjorck M, Leppaniemi A, Ejike JC, Sugrue M, Cheatham M, Ivatury R, Ball CG, Reintam Blaser A, Regli A, Balogh ZJ, D’Amours S, Debergh D, Kaplan M, Kimball E, Olvera C; The Pediatric Guidelines Sub-Committee for the World Society of the Abdominal Compartment Syndrome: Intra-abdominal hypertension and the abdominal compartment syndrome: updated consensus definitions and clinical practice guidelines from the World Society of the Abdominal Compartment Syndrome. Intensive Care Med 2013, in press.

-3 Cheatham ML, Malbrain ML, Kirkpatrick A, Sugrue M, Parr M, De Waele J, Balogh Z, Leppäniemi A, Olvera C, Ivatury R, D'Amours S, Wendon J, Hillman K, Wilmer A: Results from the International Conference of Experts on Intra-abdominal Hypertension and Abdominal Compartment Syndrome. II. Recommendations. Intensive Care Med 2007;33:951-962.

-4 Chua TC, Moran BJ, Sugarbaker PH, Levine EA, Glehen O, Gilly FN, Baratti D, Deraco M, Elias D, Sardi A, Liauw W, Yan TD, Barrios P, Gómez Portilla A, de Hingh IH, Ceelen WP, Pelz JO, Piso P, González-Moreno S, Van Der Speeten K, Morris DL: Early- and long-term outcome data of patients with pseudomyxoma 
Sabbagh et al.: A New Etiology for the Abdominal Compartment Syndrome: Pseudomyxoma Peritonei

peritonei from appendiceal origin treated by a strategy of cytoreductive surgery and hyperthermic intraperitoneal chemotherapy. J Clin Oncol 2012;30:2449-2456.

5 Taflampas P, Dayal S, Chandrakumaran K, Mohamed F, Cecil TD, Moran BJ: Pre-operative tumour marker status predicts recurrence and survival after complete cytoreduction and hyperthermic intraperitoneal chemotherapy for appendiceal pseudomyxoma peritonei: analysis of 519 patients. Eur J Surg Oncol 2014;40:515-520.

6 Nawaz A, Karakurum A, Weltman D, Shehata A, Mohammed I, Hadjiyane C, Pellecchia C: Pseudomyxoma peritonei manifesting as intestinal obstruction. South Med J 2000;93:891-893.

7 Mohamed F, Moran BJ: Morbidity and mortality with cytoreductive surgery and intraperitoneal chemotherapy: the importance of a learning curve. Cancer J 2009;15:196-199.
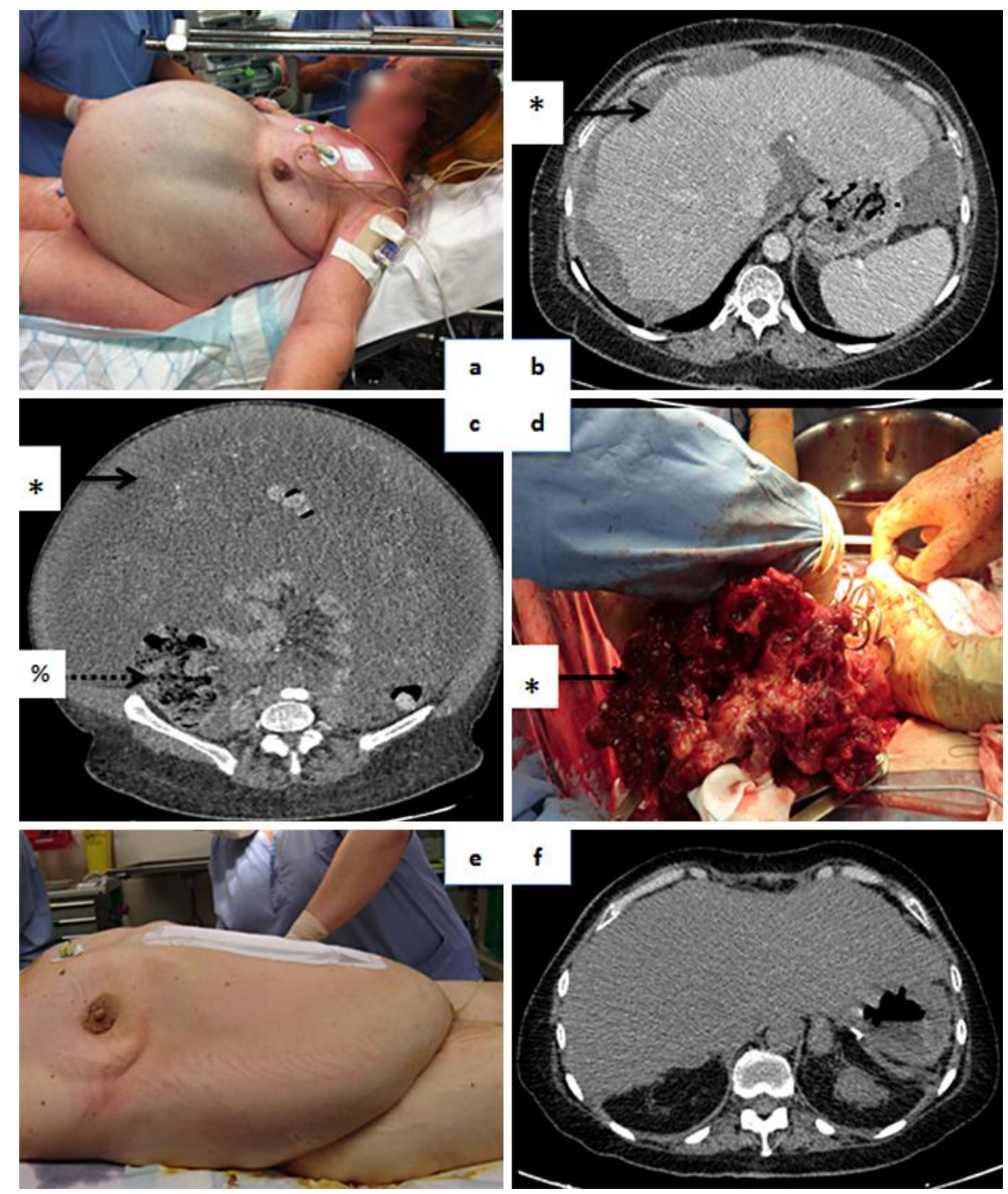

Fig. 1. a Preoperative view of the abdomen showing an abdominal distension due to the intra-abdominal mucin. b Horizontal view of the preoperative CT scan. * Mucin is making a scalloping aspect on the liver (black arrow). c Horizontal view of preoperative CT scan. There is mucin that is responsible of the abdominal compartment syndrome and a compression of the intra-abdominal organs at the mesentery. * Mucin (black arrow). \% Compression of the intra-abdominal organs (disrupted black arrow). d Peroperative view. The omentum has been removed. * Omental cake (black arrow). e Abdomen at the end of the first procedure. The mucin has been removed. $\mathrm{fCT}$ scan, 1 year after the HIPEC procedure. 